\title{
First results from the Penn State Allsky Imager at the Arecibo Observatory
}

\author{
Ilgin Seker ${ }^{1}$, John D. Mathews ${ }^{1}$, Johannes Wiig ${ }^{1}$, Paloma F. Gutierrez ${ }^{1}$, Jonathan S. Friedman², and Craig A. Tepley ${ }^{2}$ \\ ${ }^{1}$ Communications \& Space Sciences Laboratory (CSSL), Penn State University, PA, U.S.A. \\ ${ }^{2}$ National Astronomy and Ionosphere Center, Arecibo Observatory, Arecibo, PR, U.S.A.
}

(Received July 7, 2006; Revised September 26, 2006; Accepted October 31, 2006; Online published March 23, 2007)

\begin{abstract}
The Penn State Allsky imager (PSASI), a user-owned-public-access (UOPA) instrument installed at Arecibo Observatory (AO: $18.3^{\circ} \mathrm{N}, 66.75^{\circ} \mathrm{W}$; altitude: $350 \mathrm{~m}$ a.s.l.; $L=1.43$ at $300 \mathrm{~km}$; dip angle: $46^{\circ}$; geomagnetic coordinates: $29^{\circ} \mathrm{N}, 5.5^{\circ} \mathrm{E}$ ), is a CCD-based high-resolution allsky optical imager that has been collecting ionospheric airglow data at night since May 2003. The computer controlled six-position filter wheel is equipped with three filters at $630 \mathrm{~nm}$ (red), $557.7 \mathrm{~nm}$ (green), and $777.4 \mathrm{~nm}$ (near-IR), respectively, which correspond to ionosphere-related oxygen emissions. The imager data, taken for more than 3.5 years now, is being used to study various ionospheric processes, such as mapped equatorial spread-F plumes, E-region gravity waves, among other, in conjunction with the AO incoherent scatter radar (ISR), mesosphere and lower thermosphere (MLT) metals lidar, and other instruments, including microbarographs. Data availability and quality as well as specific airglow events on both small/large time/spatial scales are examined, categorized, and made freely available at a data-server website. Our goal here is to briefly review the airglow science enabled by allsky imaging at AO, to describe the instrument and the data-collection methodology, and to present some of the significant results, including airglow events that correspond to ISR results.
\end{abstract}

Key words: Penn State Allsky Imager, Arecibo Observatory, ionospheric processes, airglow events, ISR results.

\section{Introduction}

In the last 10 years the development of commercial, relatively low-cost, high-sensitivity, and low-noise CCD cameras with digital readout has led to the development of science-grade, all-sky camera systems applicable for observing atmospheric airglow features. These systems with optics now typically cost US\$ 50-100K. The Penn State Allsky imager (PSASI) was located at Arecibo Observatory (AO) as a user-owned, public-access (UOPA) instrument in keeping with the "national facility" status of the observatory. At AO, PSASI is part of an instrument cluster that enables the study at an approximately 100-m scale through mesoscale ionospheric processes. The AO instrument cluster surrounds the premier instrument at $\mathrm{AO}$, the incoherent scatter radar (ISR), and includes the imager described here, the resonance fluorescence (metals) lidar systems, FabryPerot interferometer (FPI), ionosondes, a dual-frequency GPS (TEC) receiver, microbarographs, and a magnetometer (May, 2006). While normally used in all-sky $\left(180^{\circ}\right.$ FOV; field-of-view) mode-yielding mesoscale images in unfiltered (open) mode and at $557.7 \mathrm{~nm}, 630.0 \mathrm{~nm}$, and $777.4 \mathrm{~nm}$ - a narrow-FOV $\left(47^{\circ}\right)$ lens is also available for campaign-mode observations. We next review the science context of the modern CCD-based all-sky camera and note the unique capabilities and resulting science outcomes of such systems based at AO.

The ionosphere is not a stable, calm, homogenous region. Its composition and structure varies diurnally, seasonally,

Copyright (c) The Society of Geomagnetism and Earth, Planetary and Space Sciences (SGEPSS); The Seismological Society of Japan; The Volcanological Society of Japan; The Geodetic Society of Japan; The Japanese Society for Planetary Sciences; TERRAPUB and over the solar cycle, and also by latitude and altitude. It is also highly affected by atmospheric, magnetospheric, and solar events and is often unstable. Thus, there are many different phenomena seen in the ionosphere, such as ducted and gravity waves (Taylor, 1997), bores (Smith et al., 2003), sporadic-E (Mathews et al., 2001a; Kelley et al., 2003), equatorial anomaly (Kelley et al., 2000a), spreadF (ESF) and Plumes (Mendillo et al., 1997; Mathews et al., 2001b; Makela, 2004b; Makela et al., 2004a), plasma bubbles and instabilities, traveling ionospheric disturbances (TIDs) (Mendillo et al., 1997; Kelley et al., 2000b; Kelley et al., 2002), midnight temperature maximum (MTM), and brightness waves (BW) (Herrero and Meriwether, 1980; Colerico et al., 1996; Mendillo et al., 1997).

The PSASI at the Arecibo Observatory, Puerto Rico $\left(18.3^{\circ} \mathrm{N}, 66.75^{\circ} \mathrm{W}\right)$ is controlled remotely and maintained by the CSSL (Communications \& Space Sciences Laboratory) at the Penn State University (PSU) under several NSF (National Science Foundation) grants. Arecibo Observatory was a natural choice for the imager because the site is geographically in the tropics but at geomagnetic mid-latitudes, which allows $\mathrm{mid} /$ low latitude ionospheric phenomena to be observed. Figure 1 shows the geomagnetic field line geometry associated with the site and the coverage of the imager (limited to $150^{\circ} \mathrm{FOV}$ ) assuming an emission height of $300 \mathrm{~km}$. The site also has an ISR along with many other passive and active instruments (such as FPI, photometer, lidar, etc.) to observe ionosphere, which allows the fusion of data from multiple instruments. PSASI is designed to autonomously operate during moonless nights. Even though it is operated by CSSL, it is a public-access instrumentaccess is provided by means of an Apache server hosting a 

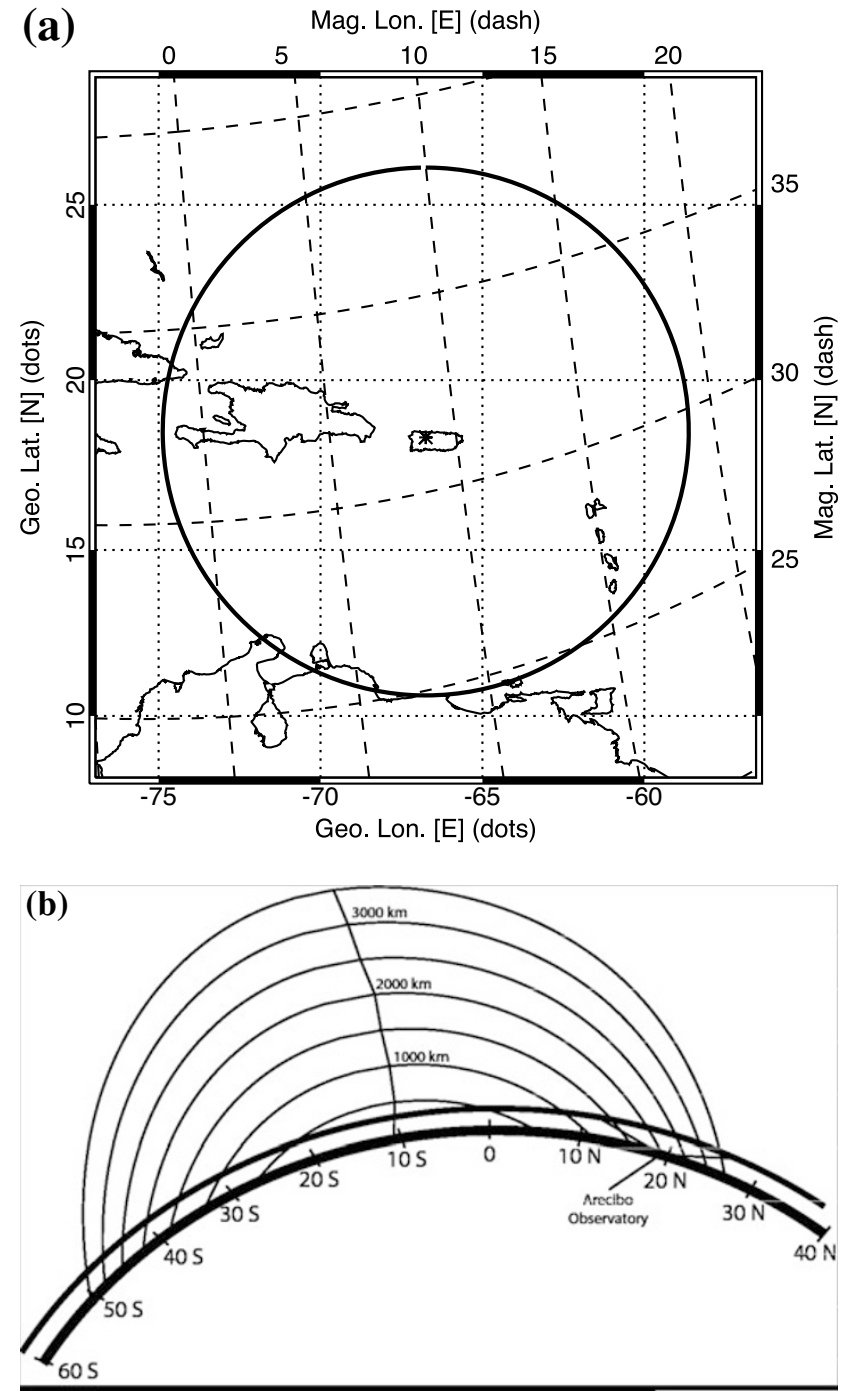

Fig. 1. (a) Geographic coordinate (latitude vs. longitude) map centered on AO showing coverage of the imager with a field of view of $150^{\circ}$ assuming an emission height of $300 \mathrm{~km}$. (b) Geomagnetic field line distribution in the magnetic meridional plane of Arecibo (latitude vs. altitude) mapping the $630-\mathrm{nm}$ airglow depletions at $300 \mathrm{~km}$ seen in the imager to an apex height of $1500-3500 \mathrm{~km}$. Altitude Adjusted Corrected Geomagnetic Coordinates (AACGM) are used (Makela, 2006).

public website that is updated automatically whenever new data are available.

The CCD-based PSASI is described in detail in the next section. It is configured to primarily monitor mesoscale Fregion processes using the fast $180^{\circ} \mathrm{FOV}$ primary lens and 557.7-nm, 630.0-nm, and 777.4-nm filters (plus open and closed) at typically 60-, 60-, and 90-s integrations, respectively ( $5 \mathrm{~s}$ at open/closed).

The responsible thermospheric chemical reactions are:

$$
\begin{aligned}
& \mathrm{O}^{+}+\mathrm{O}_{2} \rightarrow \mathrm{O}_{2}^{+}+\mathrm{O} \quad \text { Charge Exchange } \\
& \mathrm{O}_{2}^{+}+\mathrm{e}^{-} \rightarrow \mathrm{O}^{*}+\mathrm{O} \quad \text { Dissociative Recombination. }
\end{aligned}
$$

These reaction rates depend both on plasma height and number density as well as on the neutral atmosphere and atomic oxygen concentrations. The excited atomic oxygen $\left(\mathrm{O}^{*}\right)$ may be in either the $\mathrm{O}\left({ }^{1} \mathrm{D}\right)$ or $\mathrm{O}\left({ }^{1} \mathrm{~S}\right)$ state, resulting in that $\mathrm{OI}$ emission. The $\mathrm{O}\left({ }^{1} \mathrm{D}\right)$ state emission is at $630 \mathrm{~nm}$,

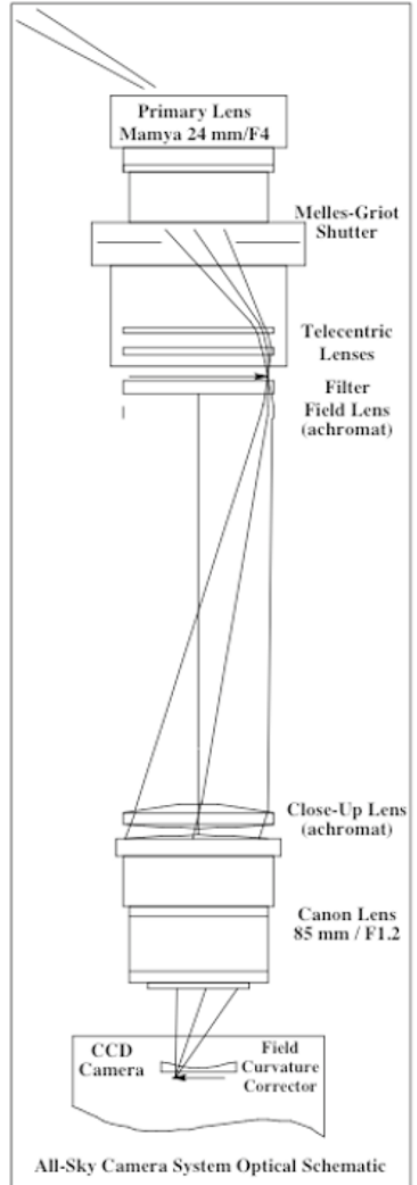

Fig. 2. Imager schematic (from Roper Scientific).

the deep-red end of the visible spectrum with a lifetime of approximately $110 \mathrm{~s}$ (producing somewhat blurred images). This emission peaks around an altitude of approximately $250 \mathrm{~km}$ and provides information on the F2-region. The $\mathrm{O}\left({ }^{1} \mathrm{~S}\right)$ state emission is at $557.7 \mathrm{~nm}$, in the green, with an approximate lifetime of $1 \mathrm{~s}$ (producing sharper images), but yields approximately $15 \%$ of the photon emission rate when compared with the 630-nm emission (Makela et al., 2001).

Although the Allsky images from the 557.7-nm emission can occasionally show intense F-region structures, this emission has a significant mesospheric component (at approximately $96 \mathrm{~km}$ in the E-region), so it can be used to analyze both F-region (e.g., depletions, plumes) and mesospheric (e.g., gravity waves) events.

The responsible mesospheric chemical reactions for the 557.7-nm emission are:

$$
\begin{aligned}
& \mathrm{O}+\mathrm{O}+\mathrm{M} \rightarrow \mathrm{O}_{2}^{*}+\mathrm{M} \\
& \mathrm{O}_{2}^{*}+\mathrm{O} \rightarrow \mathrm{O}_{2}+\mathrm{O}^{*} \\
& \mathrm{O}^{*} \rightarrow \mathrm{O}+\mathrm{hv} .
\end{aligned}
$$

The 777.4-nm emission is predominantly a result of the following reaction:

$$
\mathrm{O}^{+}+\mathrm{e}^{-} \rightarrow \mathrm{O}^{*}+\mathrm{hv} \quad \text { Radiative recombination. }
$$

Since $\mathrm{O}^{+}$is the dominant plasma constituent near the F-peak, we can assume that $\left[\mathrm{O}^{+}\right]\left(\mathrm{O}^{+}\right.$concentration $)$is 
Table 1. Figures of CCD chip performance (from Roper Scientific).

\begin{tabular}{|c|c|c|}
\hline \multicolumn{3}{|c|}{ Marconi CCD36-40 (scientific grade, MPP, back-illuminated, UV-enhancement coating) } \\
\hline Dynamic range & 16 bits & \\
\hline Spectral range & $190-1080 \mathrm{~nm}$ & \\
\hline CCD read-out noise & $2 \mathrm{e}^{-}$ & \\
\hline Single-pixel full well & $300 \mathrm{ke}^{-}$ & \\
\hline \multirow{2}{*}{ Dark current } & $@-40^{\circ} \mathrm{C}$ & $@-110^{\circ} \mathrm{C}$ \\
\hline & $0.1 \mathrm{e}^{-} / \mathrm{p} / \mathrm{s}$ & $0.5 \mathrm{e}^{-} / \mathrm{p} / \mathrm{h}$ \\
\hline \multirow{2}{*}{ Frame readout time for full frame } & @ $1 \mathrm{MHz}$ & @ $50 \mathrm{KHz}$ \\
\hline & $<1.8 \mathrm{~s}$ & $<36 \mathrm{~s}$ \\
\hline \multicolumn{3}{|l|}{ Operating temperature } \\
\hline TE cooling (air) & \multicolumn{2}{|l|}{$-40^{\circ} \mathrm{C}$} \\
\hline TE cooling (chilled liquid) & \multicolumn{2}{|l|}{$-55^{\circ} \mathrm{C}$} \\
\hline LN cooling (liquid nitrogen) & \multicolumn{2}{|l|}{$-55^{\circ} \mathrm{C}$} \\
\hline Nonlinearity@ 100 kHz & \multicolumn{2}{|l|}{$<2 \%$} \\
\hline Scan rates & \multicolumn{2}{|c|}{ “100 kHz/1 MHz” or “50 kHz/1 MHz” } \\
\hline Thermostating precision & \multicolumn{2}{|c|}{ $\pm 0.05^{\circ} \mathrm{C}$ over entire temperature range } \\
\hline System read noise & Low noise mode & High capacity mode \\
\hline @ 50 kHz conversion rate & $2.8 \mathrm{e}^{-}$ & $6 \mathrm{e}^{-}$ \\
\hline @ $100 \mathrm{kHz}$ conversion rate & $3 \mathrm{e}^{-}$ & $10 \mathrm{e}^{-}$ \\
\hline @ 1 MHz conversion rate & $10 \mathrm{e}^{-}$ & $18 \mathrm{e}^{-}$ \\
\hline Output amplifier & $250 \mathrm{ke}^{-}$ & $800 \mathrm{ke}^{-}$ \\
\hline Software selectable gains & $1 / 2 x, 1 x, 2 x$ & $1 \mathrm{x}, 2 \mathrm{x}, 4 \mathrm{x}$ \\
\hline
\end{tabular}

equal to [ $\mathrm{e}^{-}$]. Thus, the photon flux emitted at $777.4 \mathrm{~nm}$ is approximately proportional to the electron number density squared, $n_{e}^{2}$. The emission is from around the F-peak, which is at approximately $300 \mathrm{~km}$. While generally associated with auroral zone airglow features, this emission has been observed at AO.

Clearly, monitoring these emissions provides the twodimensional mesoscale context related to ionosphere height/concentration for the ISR and other AO instruments, thereby enabling study of the phenomena occurring and propagating in the ionosphere.

The purpose of this paper is to introduce the highresolution Allsky imager, the PSASI, in detail, including specifications, the hardware and software system, data statistics, and the data processing techniques along with some significant results and future research possibilities. Further detail, including manuals, posters, and presentations, can be found at the PSASI website, allsky.ee.psu.edu.

\section{The Penn State Allsky Imager (PSASI)}

\subsection{Hardware system}

The imager system was procured 3 years ago under an NSF grant. The hardware system consists of the core parts (CCD camera, controller, lenses, filters, filter wheel, shutter) and the supporting parts (dome, the mounting system, cooling system, and the gas purge system).

2.1.1 Core system Figure 2 shows the basic schematic of the core system. The CCD camera is VersArray 1300B model from Princeton Instruments. It is a high-performance, full-frame digital camera system that utilizes a back-illuminated device produced by Roper Scientific. With a $1340 \times 1300$ imaging array, $20 \times 20$ -

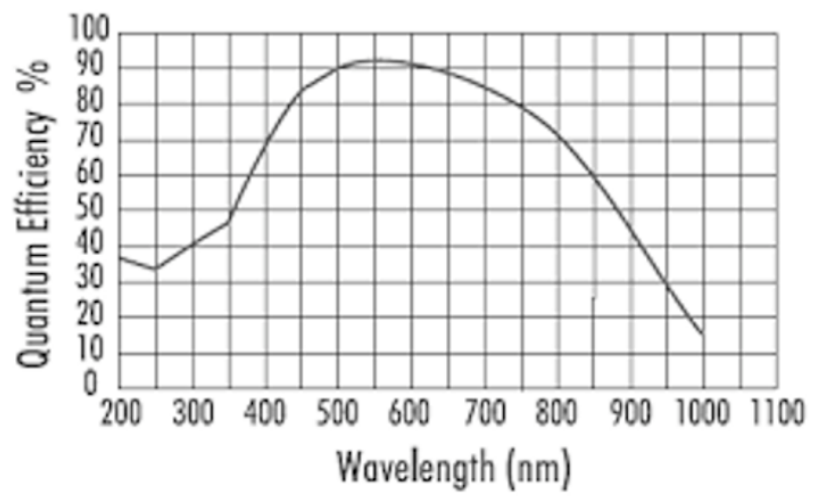

Fig. 3. Quantum efficiency of the camera (from Roper Scientific).

micron pixels, and $100 \%$ fill factor, this system provides a very large imaging area $(26.8 \times 26.0 \mathrm{~mm})$ with high spatial resolution. The CCD temperature is kept at $-40^{\circ} \mathrm{C}$ by thermoelectric cooling to reduce the dark noise. The large field of view, high quantum efficiency, low readout noise, and low binning noise make this camera ideal for a variety of low-light imaging applications, including the weak night-time airglow. Other performance figures of the CCD chip, such as noise, are listed in Table 1. The quantum efficiency of the camera, which is basically the ratio of the number of electrons generated to the number of incident photons, is given in Fig. 3; it is highly dependent on the wavelength of operation. As can be seen from the plot, at the wavelengths of the current filters, the quantum efficiency is very high. 


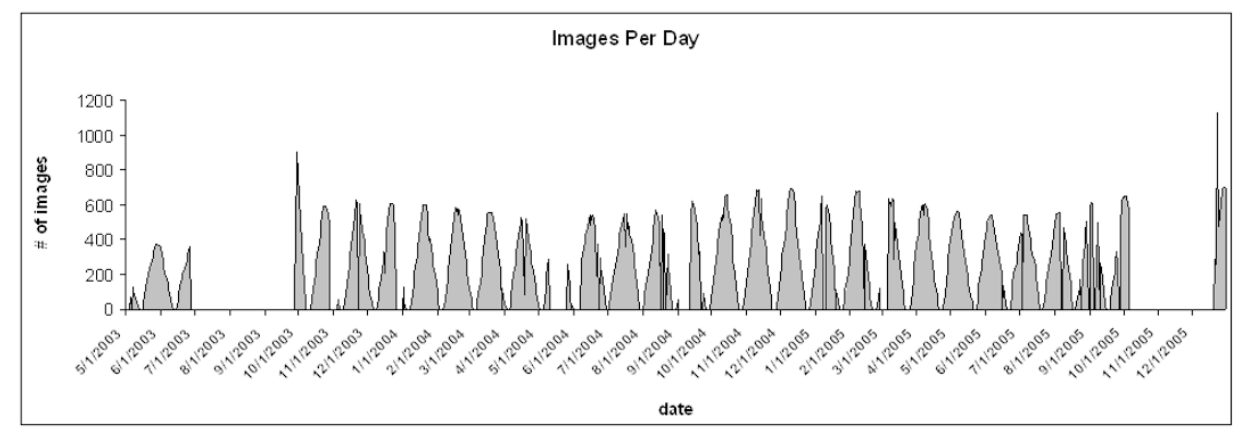

Fig. 4. Number of Images per day. The unexpected no-data nights are due to various problems that effected imager operation. The large gaps during 2003 and 2005 are due to the moisture that built up inside the camera and to the malfunctioning controller, respectively, both of which resulted in shipping of the camera back to Roper for repair. The smaller gap during June 2004 is due to the switching of the operating system of the computer that controls the camera.

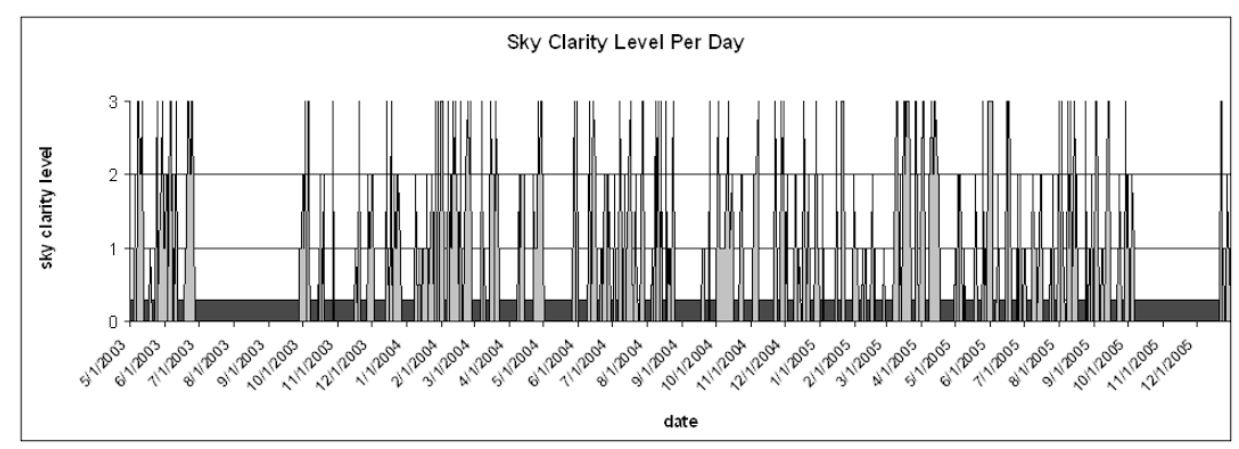

Fig. 5. Sky clarity level per day. Most nights are very cloudy (0), which limits the amount of useful data. The darker region shows the days with no data or useless data (due to full moon, instrument problems or mostly clouds).

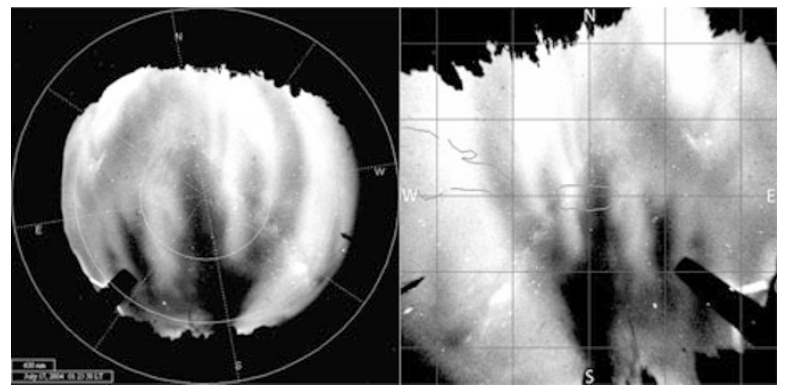

Fig. 6. (a) Spatial calibration. (b) Unwarped image (1000 km $\times 1000 \mathrm{~km})$.

The controller is a VersArray ST133A type from Roper Scientific. It controls the filter-wheel, the shutter, and the temperatures of the CCD camera and filter-wheel, and functions as the interface between the computer and the camera.

As can be seen in Fig. 2, from the top to the bottom the optical system consists of the front primary fish-eye lens (Mamya $24 \mathrm{~mm} / \mathrm{F} 4.0$ with $180^{\circ} \mathrm{FOV}$ ), telecentric lenses in front of filter-wheel (76.2/75-mm $2 \times$ plano-convex), 3inch emission filters and other built-in filters (UV, skylight, warm-up), CCD re-imaging optics (two achromats with diameters $76.2 \mathrm{~mm}$ and $72 \mathrm{~mm}$, respectively), an achromatic close-up lens, a Canon camera lens $(85 \mathrm{~mm} / \mathrm{F} 1.2)$, and a plano-concave field curvature corrector lens. The fish-eye lens creates the barrel distortion, which is the main distortion in the images due to the mapping of the image from $180^{\circ} \mathrm{FOV}$ to a planar surface. As a result, the shapes are distorted near the edges. The edges also look brighter than the central region due to longer path length and thus larger line-of-sight emissions at low elevation angles (van Rhijn effect). More detailed information about various distortions and how to correct for them is given in Section 3.1. A narrow FOV $\left(47^{\circ}\right)$ lens system for looking parallel to the geomagnetic field, which gives detailed images of localized structures, has recently been purchased for use during campaigns with the same camera system by switching the upper Allsky optical module with that having the narrow FOV.

The servo-controlled filter-wheel accommodates six 3inch filters. Its temperature is kept at room temperature by an AthenaXT16 AC temperature controller mounted below the camera in order to avoid the center wavelength shifts of the filters due to changing temperatures. Five of the six positions are currently being used (open, $777.4 \mathrm{~nm}, 630 \pm 2$ $\mathrm{nm}, 557.7 \pm 1.8 \mathrm{~nm}$, aluminum disc). A Hall-effect sensor combined with a rare earth magnet in the wheel determines the Home position.

The shutter is a modified Prontor and is moved via the "Smartmotor", which is controlled through the main controller and software. A "failsafe" front shutter system that closes the shutter in high-light conditions has been recently added (Wiig, 2004).

2.1.2 Support system The mounting system consists of adjustable rails and bars that allow the user to adjust the position and the angle of the camera. The dome is acrylic and heated by heating tapes surrounding the base perimeter. Since the AO site is quite hot and humid, moisture is a 
very common problem with the optical instruments. These tapes prevent moisture from accumulating inside and on the dome. In order to keep the system at the proper operating temperature and within the acceptable humidity range, an $\mathrm{A} / \mathrm{C}$ unit and a gas purge system is being used in addition to the filter-wheel and CCD temperature controllers. The argon gas purge drying system has recently been replaced by a dry-air unit (Commercial Energy Specialists, Jupiter, Fla.; model GD PDA20 PSA), which is more effective in dealing with the common moisture problem (Wiig, 2004).

\subsection{Software system}

The entire software control/analysis system is designed to function autonomously. The main software to control the Allsky imager is the automated Camera Data Acquisition Software (CDAS) developed by Jonathan Makela and Mike Nicolls at Cornell University. CDAS automatically adjusts the filters and records the images during the dark night periods. The conditions are: $2 \times 2$ binning and exposure times for $630 \mathrm{~nm}, 557.7 \mathrm{~nm}$, and $777.4 \mathrm{~nm}$; open and dark positions of $60 \mathrm{~s}, 60 \mathrm{~s}, 90 \mathrm{~s}, 5 \mathrm{~s}, 5 \mathrm{~s}$, respectively. The data acquired is transferred in near-real-time from the PC at $\mathrm{AO}$ to the MAC data-server at PSU via various scripts and secure communication protocols such as SSH and synchronization programs such as RSYNC. The data stored in the MAC server at PSU is automatically processed by using Perl scripts and codes to create the quick look plots and update the related web pages. All of the raw data and the results are published online using web-publishing software. The main software used to process data and create plots is the Interactive Data Language (IDL). These codes are available on request (Seker and Mathews, 2004).

Occasionally, when the system crashes or the filter-wheel gets stuck at one position, the user needs to restart the computer at $\mathrm{AO}$ or power cycle the imager. In order to avoid time delays, this operation has also been automated by using two remote control devices called iBoot, which allow the user to control the power of the imager and the computer separately from any computer in the world that has an internet connection. iBoot can also autodetect and restart the computer once it crashes by using a pinging method.

\subsection{Public access (website: allsky.ee.psu.edu)}

An automated website for PSASI and the digital barometers (and magnetometer-March 2006), which are also UOPA, is available to the community for sharing and easy access to the data. The site is updated in near-real-time, and movies of each night's results are updated on a daily basis. Quickview and full data are available at tabs: "All-sky Imager" and "Barograph".

Under the "All-sky Images" tab, the latest five JPEG images (updated in real-time) are displayed directly for a quick look. Other information tabs include:

- "System Description" includes documents, posters, and presentations that provide some information on the imager. The detailed specifications and photos of PSASI can also be found here.

- "Latest Movies" link takes the user to the previous night's MPEG movies for each filter (including no filter and dark image movies). These daily MPEGs are excellent for a fast overview while searching for events.
- "Archives" are available for downloading data in JPEG, MPEG, and TIFF formats. TIFF data include raw data and header, and requires user login. Login access can be provided for those interested upon request.

- The "Calendar" link allows the user to select the day of interest, from a calendar, and displays related data. A color-code is embedded into the calendar, thereby letting the user see the information quality of data, such as cloud cover levels. This is updated monthly.

- The "Rated Events" link lists and sorts the days during which interesting events were visible along with the cloud cover level. Clicking the day shows the MPEG movie of that day.

- Under the "Barometric Data" tab, the pressure data from the digital microbarographs is shown. Raw data (also requires login), daily and weekly plots are available. Daily plots are updated approximately every $3 \mathrm{~h}$. More information on the barometer can be found in system description web-page.

Other than these tabs, the website provides links to useful websites, such as the Puerto Rico weather image from the GOES satellite, the Puerto Rico seismic network, the SPIDR space database, the CEDAR and the Perkins Instability pages. All data users pass through the "Data Use Rules" tab to obtain passwords and/or to login to obtain data (Seker and Mathews, 2004).

\section{Data}

\subsection{Data processing techniques}

After the data arrive at the PSU server, they are processed at various levels that we outline next. Here, the outlines of these techniques will be briefly introduced. Detailed results employing these techniques will be the topic of future papers.

The "raw" allsky images include many different unwanted effects for which we perform a variety of corrections. These effects may vary spatially and temporally. The first correction is to remove the unwanted image components or properties. Some of these can be calculated exactly, but most require assumptions or approximations.

Briefly, the corrections carried out on the way to the final, flat-fielded, and calibrated image include (Makela, 2004c):

1. Dark Count Correction. The dark count of the CCD detector largely depends on its temperature. PSASI is programmed to take dark images every four cycles. The dark count level is subtracted from such an image.

2. Star Removal. The stars are removed using an IDL routine that compares each pixel value to the median of the surrounding pixels and removes the star if the difference exceeds threshold. Higher luminosity stars create more blurring in the removal process. Another problem stars or other intense light sources cause is "ghosting", which is defined as persistent or residual images that occur in CCD detectors due to photoelectrons trapped at impurity sites of the substrate (Rest et al., 2002).

3. Background Correction. The contamination due to background continuum emission can be removed by using an interference filter at a wavelength slightly different from the emission line. Although PSASI does not have interference filters, it has built-in UV, skylight, and warm-up filters 
Table 2. Most spectacular events from PSASI.

\begin{tabular}{|c|c|c|c|c|c|c|c|c|c|}
\hline \multirow{2}{*}{ Date } & \multirow{2}{*}{ Filter } & \multirow{2}{*}{ Type } & \multirow{2}{*}{$\begin{array}{l}\text { Cloud } \\
\text { Level }\end{array}$} & \multirow{2}{*}{$\begin{array}{l}\# \text { of } \\
\text { Images }\end{array}$} & Aug 8, 2004 & 2 & $b, c$ & 0 & 296 \\
\hline & & & & & Aug 11, 2004 & $2(\mathrm{~L})$ & a, c, d & 0 & 453 \\
\hline May 29,2003 & 1 & $a, b$ & 0 & 368 & Aug 14,2004 & 2 & $\mathrm{~b}$ & 0 & 551 \\
\hline Nov 28,2003 & 2 & $b, c$ & 1 & 390 & $\operatorname{Aug} 23,2004$ & 2 & $b, c$ & 1 & 315 \\
\hline Nov 30,2003 & 2 & $a, b$ & 2 & 281 & Aug 24, 2004 & 1 & $b, e$ & 0 & 248 \\
\hline \multirow{3}{*}{$\operatorname{Dec} 22,2003$} & 1 & $\mathrm{~b}$ & \multirow{3}{*}{2} & \multirow{3}{*}{608} & \multirow{2}{*}{ Oct 9,2004} & 1 & $\mathrm{~b}$ & \multirow{2}{*}{2} & \multirow{2}{*}{491} \\
\hline & \multirow[b]{2}{*}{$2(\mathrm{~L})$} & \multirow[b]{2}{*}{$\mathrm{a}, \mathrm{b}, \mathrm{c}$} & & & & 2 & $a, b, d$ & & \\
\hline & & & & & Oct 10,2004 & 1 & a & 1 & 547 \\
\hline Dec 23,2003 & $2(\mathrm{~L})$ & $b, c$ & 1 & 607 & Oct 16,2004 & 2 & $a, c$ & 2 & 601 \\
\hline $\operatorname{Dec} 24,2003$ & 1 & $\mathrm{~b}$ & 2 & 601 & Oct 18,2004 & 2 & $\mathrm{c}$ & 3 & 474 \\
\hline Dec 25,2003 & 1 & $\mathrm{a}, \mathrm{b}, \mathrm{c}$ & 1 & 536 & \multirow{2}{*}{ Nov 7, 2004} & 1 & a, d & 0 & 491 \\
\hline Jan 21, 2004 & 1 & $\mathrm{~b}, \mathrm{c}$ & 2 & 601 & & 2 & $a, b, c$ & 0 & 491 \\
\hline $\operatorname{Jan} 24,2004$ & 1 & a, c & 1 & 451 & Dec 10, 2004 & 1 & $a, b, e$ & 1 & 698 \\
\hline Jan 26, 2004 & 1 & $\mathrm{c}$ & 0 & 399 & Dec 17,2004 & 1 & $\mathrm{c}$ & 3 & 380 \\
\hline $\operatorname{Jan} 27,2004$ & 2 & $b, c$ & 0 & 352 & Dec 31, 2004 & 1 & $\mathrm{~b}$ & 2 & 206 \\
\hline $\operatorname{Jan} 31,2004$ & 2 & $\mathrm{c}$ & 0 & 153 & $\operatorname{Jan} 15,2005$ & 2 & $\mathrm{c}$ & 1 & 406 \\
\hline Feb 12, 2004 & 2 & $a, c$ & 1 & 280 & Јап 16,2005 & 1 & $\mathrm{c}$ & 0 & 338 \\
\hline Feb 15, 2004 & 1 & $\mathrm{~b}$ & 1 & 468 & Jan 10,2000 & 2 & a & & 358 \\
\hline Feb 17, 2004 & 2 & c & 0 & 583 & Feb 8,2005 & $2(\mathrm{~L})$ & $\mathrm{c}$ & 2 & 677 \\
\hline Feb 22, 2004 & 1 & $\mathrm{~b}$ & 1 & 518 & Feb 10, 2005 & $2(\mathrm{~L})$ & $\mathrm{c}$ & 2 & 622 \\
\hline Feb 26, 2004 & $2(\mathrm{~L})$ & $b, c$ & 0 & 318 & Feb 17, 2005 & 1 & a, c & 1 & 185 \\
\hline & 1 & $\mathrm{~b}$ & & & Mar 9,2005 & 2 & $a, b, c, d$ & 1 & 592 \\
\hline Feb 27, 2004 & 2 & $a, b, c$ & 0 & 266 & Mar 11,2005 & $2(\mathrm{~L})$ & $a, b, c$ & 0 & 634 \\
\hline Mar 15, 2004 & 1 & a, c & 2 & 454 & Mar 17, 2005 & $2(\mathrm{~L})$ & $\mathrm{c}$ & 0 & 253 \\
\hline Mar 16,2004 & $2(\mathrm{~L})$ & $a c$ & 0 & $\begin{array}{l}444 \\
495\end{array}$ & May 4, 2005 & 2 & $a, b, d$ & 3 & 532 \\
\hline & $\frac{2(2)}{1}$ & $d$ & & & May 7,2005 & 1 & d & 3 & 564 \\
\hline $\operatorname{Mar} 18,2004$ & 2 & $a, c$ & 1 & 558 & Jun 1,2005 & 2 & $b, c, d$ & 0 & 423 \\
\hline Mar 19, 2004 & $2(\mathrm{~L})$ & $\mathrm{c}$ & 3 & 554 & $\operatorname{Jun} 2,2005$ & 2 & $b, c, d$ & 0 & 460 \\
\hline Mar 21, 2004 & 2 & $b, c, d$ & 1 & 551 & $\operatorname{Jun} 7,2005$ & 2 & $b, d$ & 2 & 540 \\
\hline & $1(\mathrm{R})$ & $b, c$ & & & Ju19 2005 & 1 & $b, e$ & 1 & 471 \\
\hline $\operatorname{Mar} 22,2004$ & $2(\mathrm{~L})$ & $\mathrm{b}$ & 1 & 528 & July, 2000 & 2 & $b, c, d$ & 1 & $4 / 1$ \\
\hline & 1 & $\mathrm{~b}$ & 1 & & Jul11,2005 & 1 & a & 2 & 397 \\
\hline Apr 12,2004 & 2 & $\mathrm{a}, \mathrm{b}, \mathrm{c}$ & 1 & 364 & Aug 11, 2005 & 2 & $a, b, d$ & 0 & 385 \\
\hline & 1 & $\mathrm{~b}$ & 1 & & Sep 4,2005 & 2 & $b, d$ & 0 & 606 \\
\hline Apr 14, 2004 & $2(\mathrm{~L})$ & $\mathrm{b}, \mathrm{c}$ & 1 & 462 & Sep 30, 2005 & 2 & $b, c$ & 2 & 618 \\
\hline Apr 23, 2004 & 2 & $c, d$ & 1 & 367 & Oct 1,2005 & 2 & $a, b, d$ & 1 & 648 \\
\hline & 1 & $b, d$ & & & Dec 30, 2005 & 1 & $\mathrm{~b}$ & 2 & 699 \\
\hline Apr 26,2004 & 2 & $\mathrm{~b}, \mathrm{c}$ & 0 & 220 & Dec 31,2005 & 1 & $\mathrm{~b}$ & 3 & 695 \\
\hline Apr 27, 2004 & 2 & $b, d$ & 0 & 176 & & & & & \\
\hline Jun 15,2004 & $2(\mathrm{~L})$ & $a, b, c, d$ & 0 & 541 & $\begin{array}{l}\text { Cloud Level } \\
0=\text { cleat }\end{array}$ & & & & \\
\hline Jun 16,2004 & 1 & $\mathrm{~b}$ & 1 & 484 & $1=$ bit cloud & & & & \\
\hline Jun 16, 2004 & $2(\mathrm{~L})$ & b, d & 1 & 484 & $2=$ moderat & y cloud & & & \\
\hline $\operatorname{Jun} 19,2004$ & 2 & $a, b, c, d$ & 3 & 515 & $3=$ very clou & & & & \\
\hline Jun 24, 2004 & 2 & b, c & 1 & 294 & $1=630 \mathrm{~nm}$ & & & & \\
\hline Jun 25, 2004 & 2 & a, $c$ & 1 & 252 & $\mathrm{a}=$ equatoris & plume & & & \\
\hline Jun 26,2004 & 1 & $\mathrm{~b}$ & 1 & 210 & $\mathrm{~b}=$ depletior & bands & & & \\
\hline $\operatorname{Jun} 20,2004$ & 2 & a, c, d & 1 & 210 & $c=$ cloud-lik & enhanc & ment & & \\
\hline Jul 12, 2004 & 1 & $\mathrm{~b}$ & 1 & 418 & $\mathrm{~d}=$ midnight & tempera & ure maxim & $(\mathrm{M}$ & \\
\hline Jul 13, 2004 & 2 & $b, c, d$ & 3 & 466 & $e=$ brightnes & wave & & & \\
\hline Jul 14, 2004 & 1 & $\mathrm{~b}$ & 2 & 511 & $2=557.7 n$ & & & & \\
\hline Jul 15, 2004 & $2(\mathrm{~L})$ & a, d & 2 & 553 & $a=$ regular $w$ & aves & & & \\
\hline Jul 16, 2004 & 1 & $\mathrm{a}, \mathrm{b}$ & 1 & 553 & $\mathrm{~b}=$ turbulen & type wa & & & \\
\hline Jul 16,2004 & $2(L)$ & $a, b, c$ & 1 & 553 & $c=$ ripple-ty & waves & & & \\
\hline Jul 17, 2004 & $2(\mathrm{~L})$ & $b, d$ & 0 & 362 & $d=$ wave fro & & & & \\
\hline & 1 & $\mathrm{e}$ & 1 & & & & & & \\
\hline & 2 & $a, b, d$ & 1 & 397 & * Bold event & are sho & $\mathrm{V} n$ in the in & oduo & \\
\hline Ju1 23, 2004 & 2 & $\mathrm{~b}$ & 2 & 359 & paper. & & & & \\
\hline Ju1 24, 2004 & 1 & a & 3 & 300 & ${ }^{*} \mathrm{~L}=\mathrm{LIDAF}$ & running & & & \\
\hline Ju1 25, 2004 & 1 & $\mathrm{~b}$ & 3 & 270 & * $\mathrm{R}=\mathrm{Radar}$ & lata avai & able & & \\
\hline Ju1 26,2004 & 1 & $a, b$ & 2 & 202 & & & & & \\
\hline
\end{tabular}

for different purposes. Currently, the skylight filter (SL-1B) is being used to decrease glare.

4. Van Rhijn Effect. The images appear to be brighter at the edges because of the larger emission layer for lower elevation look angles (although the attenuation is also higher). This effect can be removed either by fitting a twodimensional curve to the low-frequency portion of the image and dividing the image by this curve, or by modeling the emission layers using some geometry. Currently, the fitting method is being used whenever required.

5. Lens Vignetting. The lenses tend to transmit less light at low elevation angles. This effect can be removed by using a calibration source or a Lambertian surface model (optics); however, the removal procedure for the Van Rhijn effect automatically corrects for this also.

6. Spatial Location. Required whenever the imager is moved. Spatially locating the image is done in CDAS by rotating the image using star map matching to adjust the directions (e.g., to make the north direction upward).

7. Absolute Intensity. The received intensity per pixel (pixel count) is just a relative number. In order to convert it to luminous flux (Rayleighs), photometric calibration is carried out. At AO, a known $\mathrm{C} 14$ source is used to calibrate the camera, providing a conversion factor from relative to absolute luminous flux.

After removing the effects mentioned above, the image is unwarped (projection of the image to a planar emission surface) in order to remove the spatial distortion due to the 


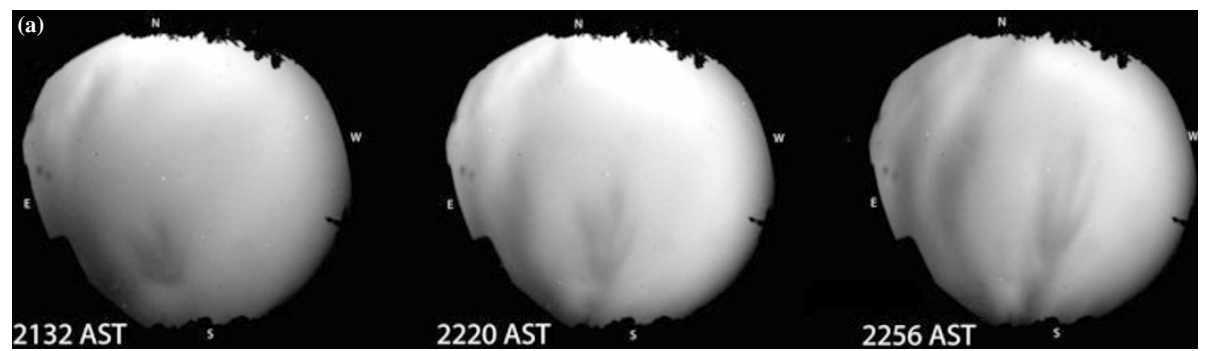

(b)
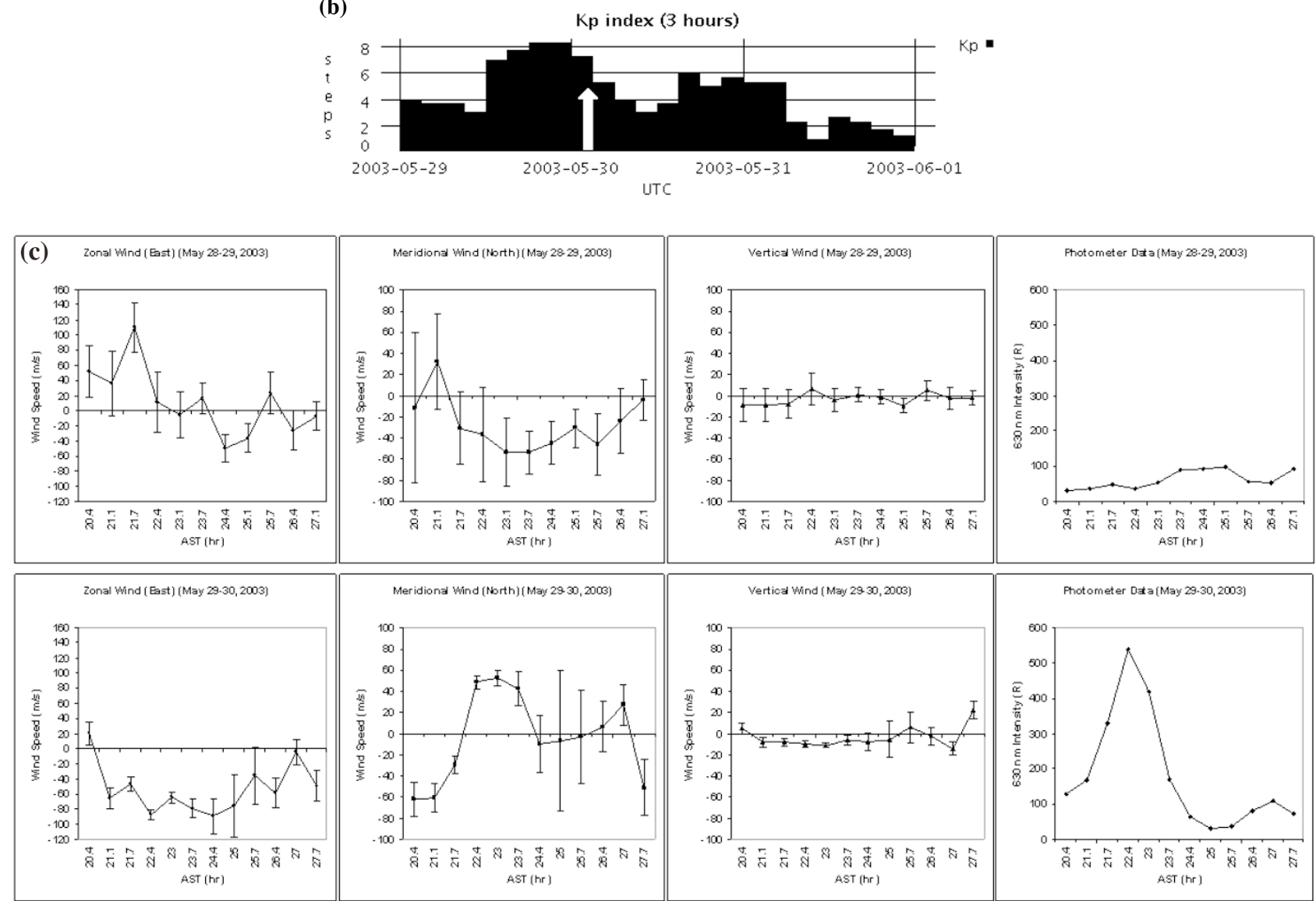

Fig. 7. (a) An equatorial plume event from 29 to 30 May 2003. (b) Kp (from SPIDR database) during event (UT = AST +4 ). (c) FPI wind and photometer 630-nm emission intensity data for the event and the night before. Note the reversal of the 630-nm winds during this event.

fish-eye lens. Since the emission height is also known, the unwarped image can also be projected onto a map with longitudinal and latitudinal axes. CDAS has a built-in option to do this mapping (an example is shown in Section 3.3.) (Makela, 2004c).

\subsection{Data statistics}

PSASI has been collecting data during dark moon-down periods since April, 2003. Excluding the JPEG images and the daily movies, the raw data (TIFF) occupy approximately $170 \mathrm{~GB}$ of disk space. The whole dataset, including the JPEGs and movies, is transferred to PSU, and a back-up copy is made to another computer at PSU on a regular basis to protect against data loss.

Figure 4 shows the number of images collected per day. The periodicity is due to the lunar cycle. During the full moon period, the imager is inactive for approximately four nights. Figure 5 shows the sky clarity level per day. The clear nights are labeled as level 3 , whereas the nights cov- ered totally with clouds are labeled as 0 . As can be seen, most of the nights are cloudy at $\mathrm{AO}$ due to the fact that it is a tropical, humid region. Although the AO site has many advantages for Allsky imaging science, this fact alone has a major negative effect on the number of nights with useful data.

All data are scanned every morning, and a very detailed log-book, including the data quality, quantity and the airglow information, is kept regularly. The log-book method is very useful for locating a past event or for statistical purposes. Table 2 (also on http://allsky.ee.psu.edu/ allsky/favorite.htm) shows the days of the most spectacular events during the period of operation. The actual number of events is much higher, but the events shown here are the most spectacular ones. The most spectacular events occurred on 80 nights (13 for both $630,557.7 \mathrm{~nm}, 26$ for 630 $\mathrm{nm}$ only; 41 for $557.7 \mathrm{~nm}$ only), 13 of which are discussed in the next section. Detailed explanations, further catego- 


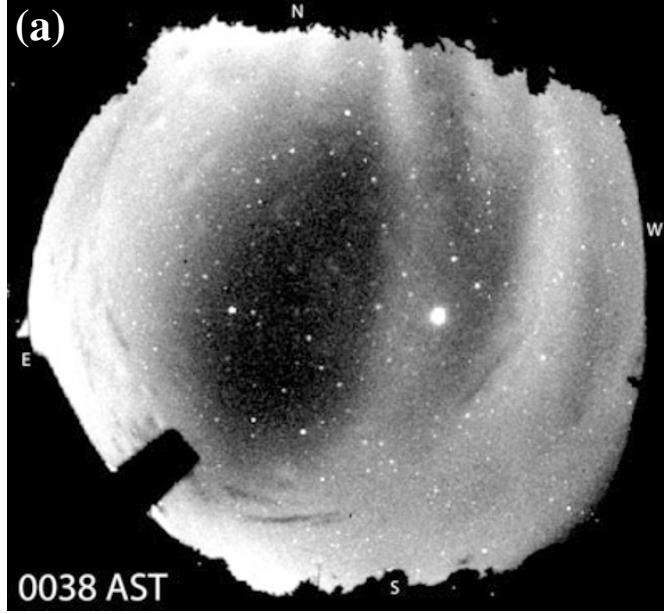

(b)

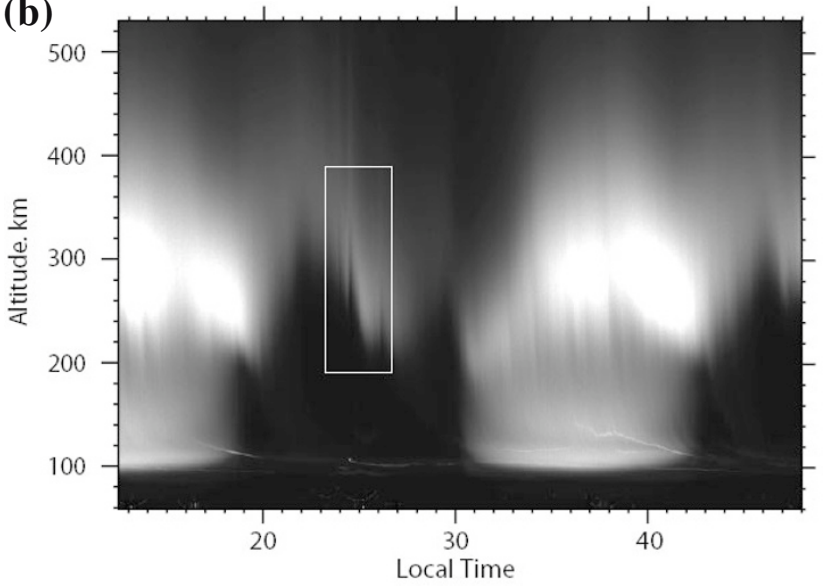

Fig. 8. Plasma depletion bands observed using the 630-nm filter extending roughly from north to south and moving towards the west during the night of 22-23 March 2004 (Kelley et al., 2000b). The Arecibo incoherent scattering radar was also running and recorded the depletion bands that are "embedded" in the classic midnight collapse structure (Behnke, 1970; Behnke and Harper., 1973; Colerico and Mendillo, 2002).

rization, and the statistics of these will be the topic of future papers.

\subsection{Significant events}

This section presents a variety of significant events seen at $630 \mathrm{~nm}$ and $557.7 \mathrm{~nm}$. Several images in local Atlantic Standard Time (AST) are provided in order to give an idea about the motion of the structure or waves. Below each image set, information (time/date, filter, etc.) about the event is provided. Movies are available at the website (http://allsky.ee.psu.edu/allsky/intropaper.htm). As this paper introduces the PSASI, the events presented below should be considered as introductory examples from the many events that have been observed thus far.

Figure 6(a) gives an example of spatial calibration using a star map. CDAS is used to perform this orientation verification and applies it to all future image headers. For all of the images, the geographical directions are as shown in this image. Figure 6(b) is the result of mapping the image to the geographical coordinates which is the so-called "unwarped image" with a grid size of $200 \times 200 \mathrm{~km}^{2}$. The contour in the middle shows the island of Puerto Rico, and the location of $\mathrm{AO}$ is marked.

Figure 7(a) shows a 630-nm event from 29 to 30 May

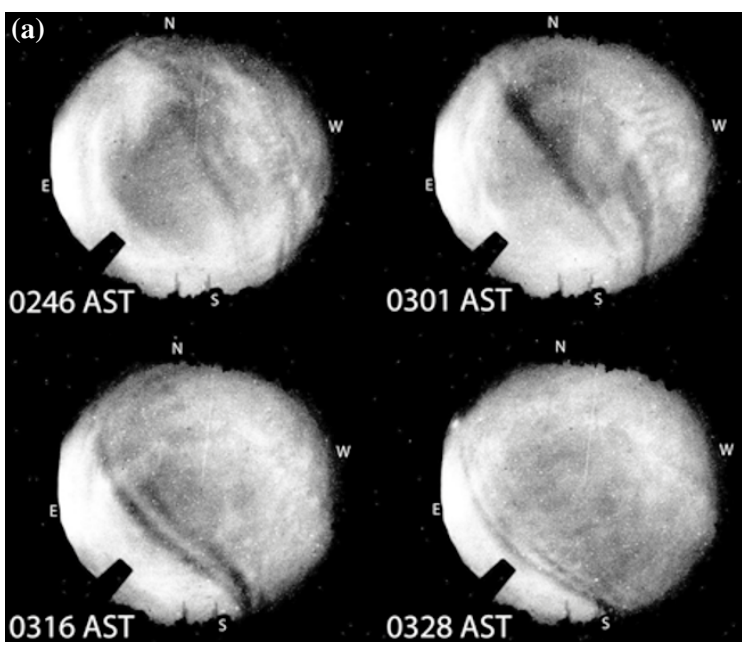

(b)

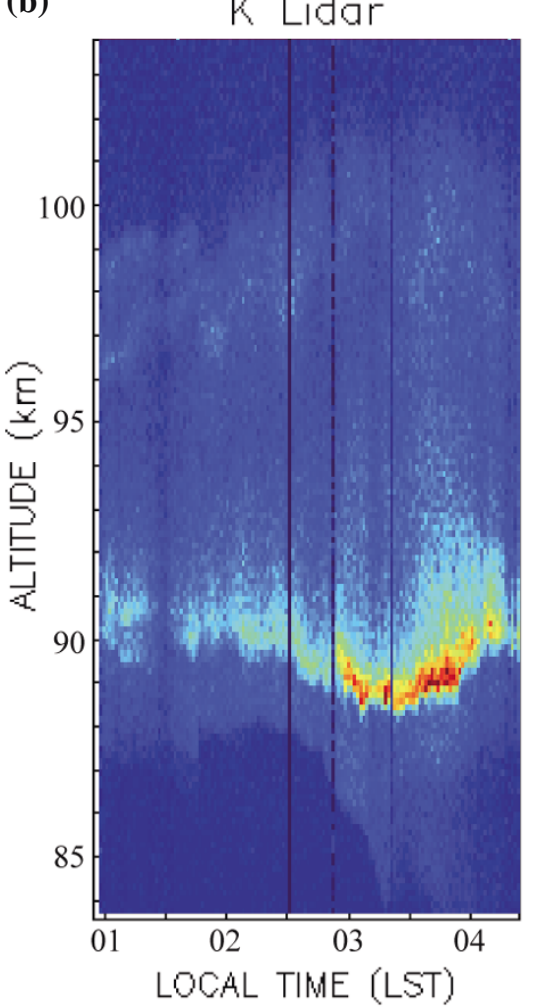

Fig. 9. A mesospheric narrow band depletion structure from 15 to 16 July 2004, which is a rare event seen in $557.7 \mathrm{~nm}$. The lidar was also running.

2003. This kind of fractal structure (seen near the center of the 2220 AST image) extending from the southeast to northwest is commonly called an "equatorial plume" due to its plume-like shape and apparent relationship to equatorial spread-F plumes (Makela et al., 2004a; Makela, 2004b). These events are usually associated with high geomagnetic activity, as is the case here ( $K p \sim 7$; Fig. 7(b)) (Sahai et $a l ., 2000)$. The arrow in the Kp plot indicates the timespan of the event. As can be seen in Fig. 7(c), the meridional wind changes direction from south to north during the event (around 2200 AST), and the 630-nm intensity increases sharply as the ionosphere is pushed down by the northward wind. The data in Fig. 7(c) from the previous 

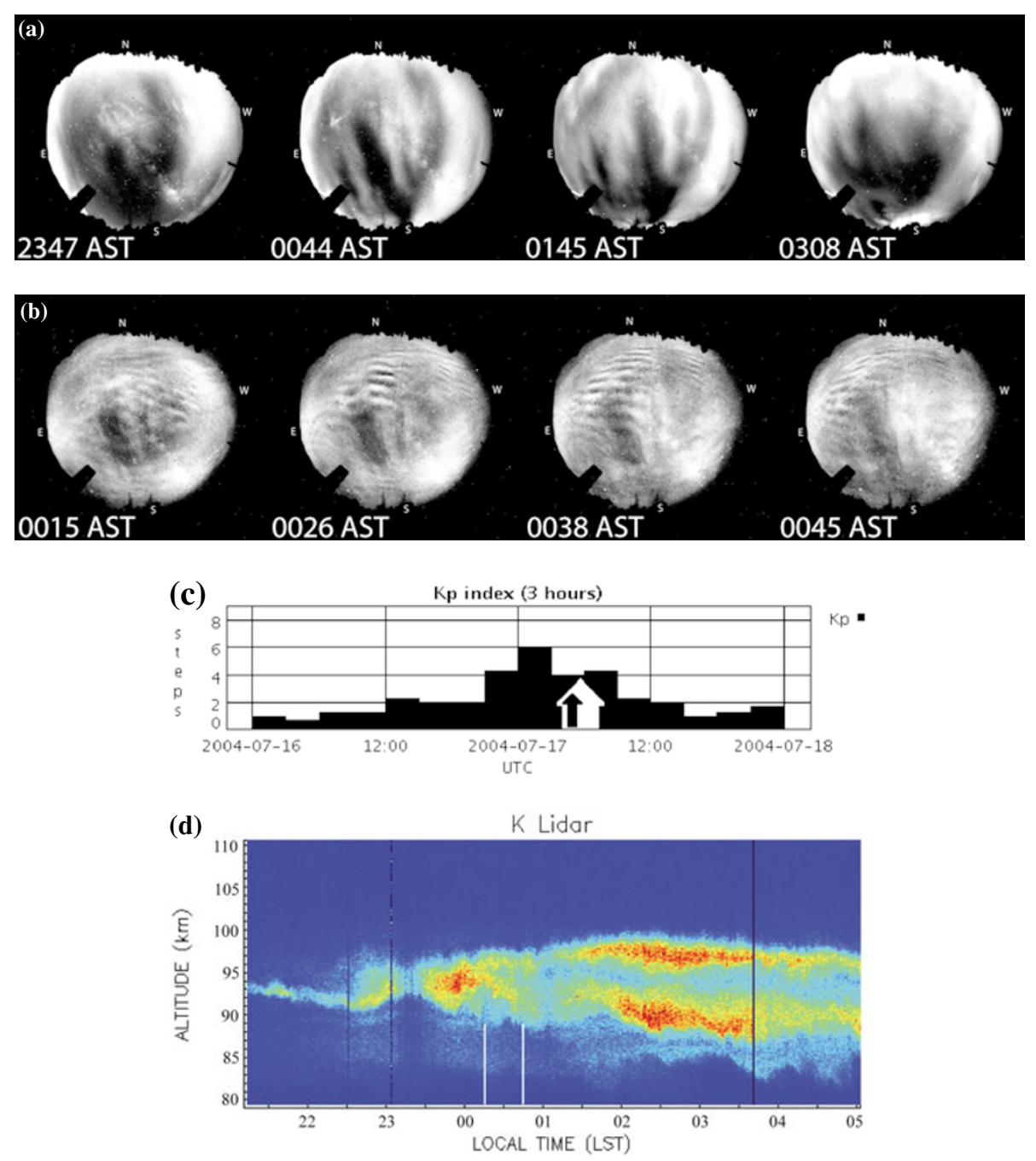

Fig. 10. A spectacular event from 16 to 17 July 2004. Both (a) $630 \mathrm{~nm}$ and (b) $557.7 \mathrm{~nm}$ show interesting structures. There is a sudden increase in (c) Kp value (from SPIDR database) during the event. (d) Lidar shows the layer breaking up. The time span of the images is shown by the two lines in (c).

night do not show these trends (imager event, meridional wind changing direction, and 630-nm intensity peak). Figure 8 shows plasma depletion bands in the F-region from 22 to 23 March 2004. Several spikes seen in ISR data in Fig. 8(b) between 11:00 p.m. and 3:00 a.m. (LT) (inside the rectangle) correspond to the bands passing through the zenith of the imager. Recent studies have shown that although these bands can not be seen during the day using the imager, they are actually part of a periodic wave pattern that is continuous (Livneh et al., 2007). From the ISR data, it looks like the first two spikes were formed as a result of the rising of the intense F-layer, whereas the third spike at approximately 2:00 a.m. (LT) was formed more by plasma depletion, as revealed by the intense midnight collapse region. The analysis of these depletion bands using the Allsky imager and incoherent scatter radar together is the subject of another paper submitted to EPS.

Figure 9 shows a rare MLT (mesosphere-lower thermosphere) bore from 15 to 16 July 2004, seen using the 557.7$\mathrm{nm}$ filter. The horizontal speed is approximately $60 \mathrm{~m} / \mathrm{s}$. Similar events have been reported at Arecibo (Smith et al., 2003). As can just be seen as a near-vertical line in the images in Fig. 9(a), the potassium lidar was also running during this event. The lidar results given in Fig. 9(b) show two distinct layers with apparent waves and an intense 90$\mathrm{km}$ layer forming around 3 a.m. Small oscillations in that potassium layer are observed when the bore passes through the center of the Allsky image.

The F-region event from 16 to 17 July 2004 in Fig. 10(a) resembles the one from 29 to 30 May 2003 (which is aligned along the northwest-southeast), except that the orientation of the structure is aligned more along the northsouth, as can be seen in the unwarped version (Fig. 6(b)). Notice that the same F-region event is so strong that it can also be seen in the 557.7-nm filter (Fig. 10(b)) due to the fact that this emission has contributions from both the mesospheric and thermospheric regions. The E-region-localized waves (ripples) in Fig. 10(b) are generated from the local distortion of the so-called band-type (gravity) waves which are usually created by the buoyancy of tropospheric disturbances. The same kind of "ripple wave" has been discussed by Chung et al. (2003). Again, as can be seen weakly in the images, the lidar was also running during the event, and the lidar results in Fig. 10(d) show a mesospheric layer 


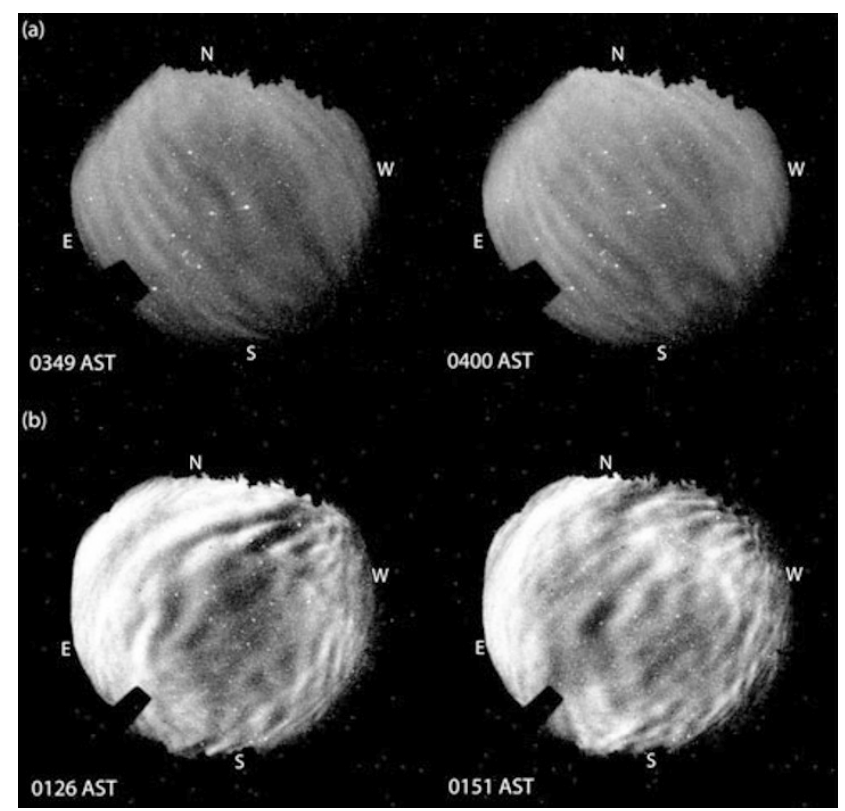

Fig. 11. (a) Regular mesospheric wave from 1 to 2 October 2005, and (b) turbulent mesospheric wave from 14 to 15 August 2004

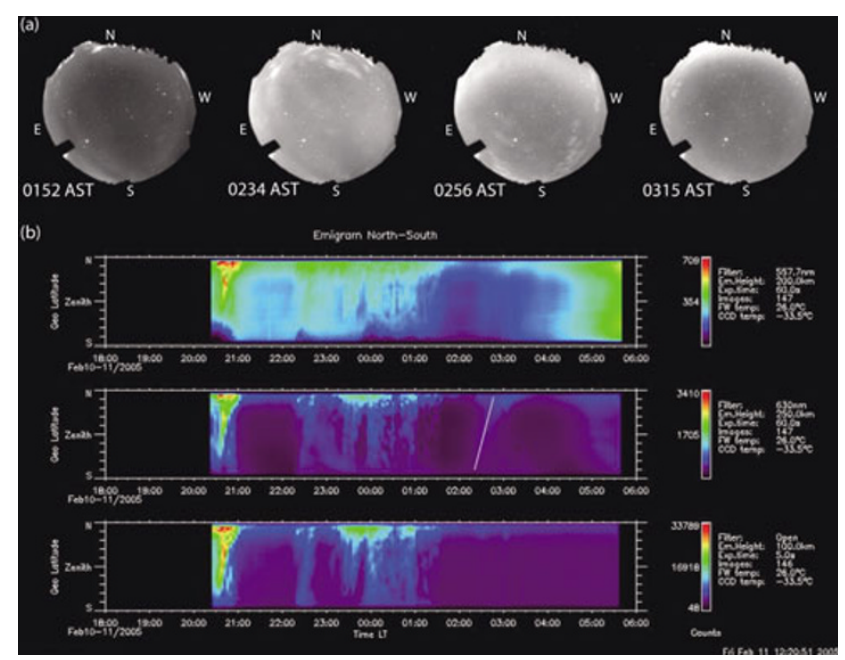

Fig. 12. Brightness Wave seen in (a) Allsky images, (b) in emigram from 10 to 11 February 2005.

breaking up into two around midnight. One recent study has also discussed a breaking wave event observed at Arecibo (Smith et al., 2005). In Fig. 10(c), the Kp values during the 630-nm (white arrow) and 557.7-nm (black arrow) events are shown, and a disturbance in $\mathrm{Kp}$ is apparent. Figure 11(a) shows a regular mesospheric wave pattern from 1 to 2 October 2005, and Fig. 11(b) shows a turbulent wave pattern from 14 to 15 August 2004; both of these events cover all of the sky, with the former moving towards the south-east, and the latter moving towards the north-east. Microbarograph data are also available on the web for surface and mesospheric wave comparison studies which might be useful in investigating the source mechanism.

Different types of mesoscale enhancement events can be seen in Figs. 12, 13, and 14. Figure 12(a) shows an eastwest-oriented brightness wave (BW) propagating towards

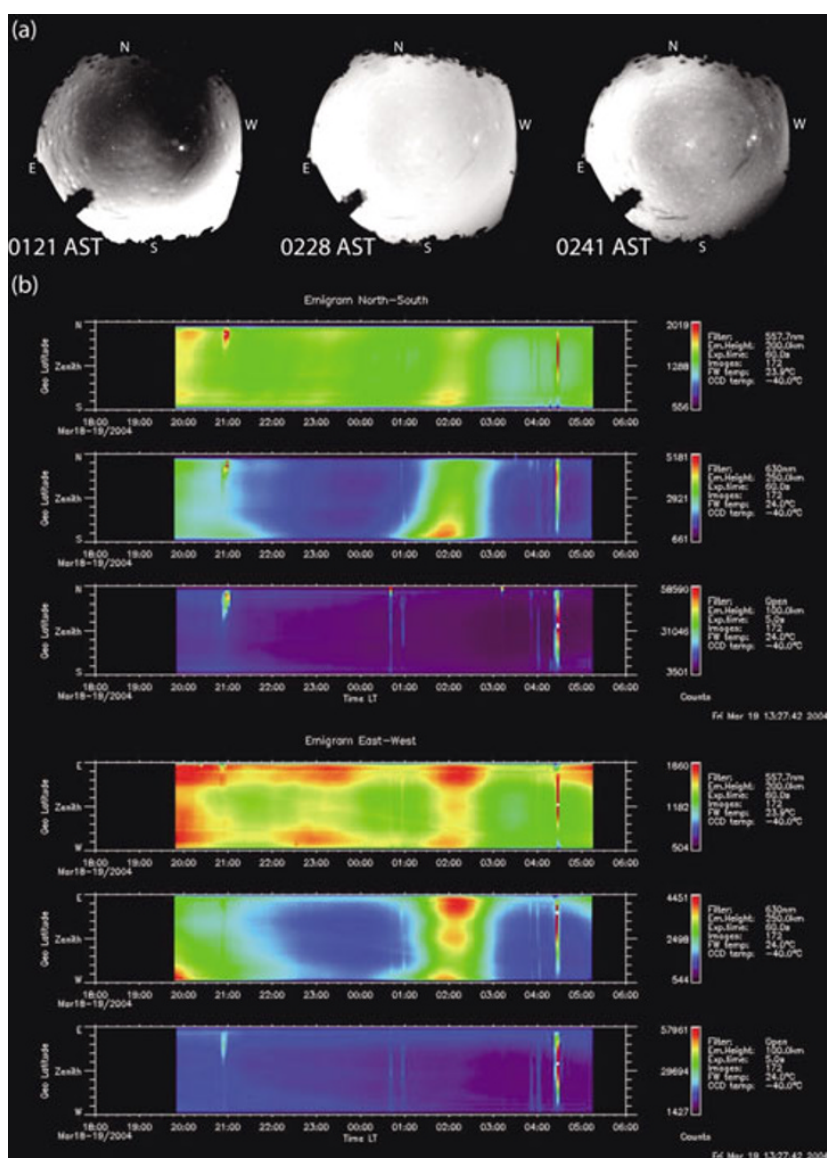

Fig. 13. MTM seen in (a) Allsky images (b) emigram from March 18 to $19,2004$.

the northeast during the night of 10-11 February 2005. This can be seen more clearly in the 630-nm keogram (which we prefer to call an emigram) in Fig. 12(b) around 2:30 a.m. (LST) (marked with a tilted line). Emigrams are the result of averaging each row or column of a flattened Allsky image and plotting these averages for each image of a particular night. Although some of the spatial information is lost, this manipulation allows for a better analysis of events which span a wide area in the image (such as the speed and direction of a $\mathrm{BW})$. From the tilt, the northward propagation speed is calculated as approximately $1000-1200 \mathrm{~km} / \mathrm{h}$ (approx $280-330 \mathrm{~m} / \mathrm{s}$ ), a result which is consistent with previous observations (Herrero and Meriwether, 1980; Colerico et al., 1996). The structures seen in the emigram between 10:00 p.m. and 1:00 a.m. (LST) are due to clouds.

Figure 13(a) shows a typical low-latitude mesoscale enhancement event which is commonly called the "midnight temperature maximum" (MTM) (or "midnight collapse" at AO) (Behnke, 1970; Behnke and Harper, 1973; Colerico and Mendillo, 2002); this occurred during the night of 18-19 March 2004. MTMs are usually large-scale events covering the FOV of the imager. The emigrams for this event both for the east-west and north-south are shown in Fig. 13(b). Strong enhancement around 2:00 a.m. slowly appears from the southwest and, after covering the whole image, slowly disappears toward the northeast. Thus, the brightness wave is apparent in both the east-west and north- 


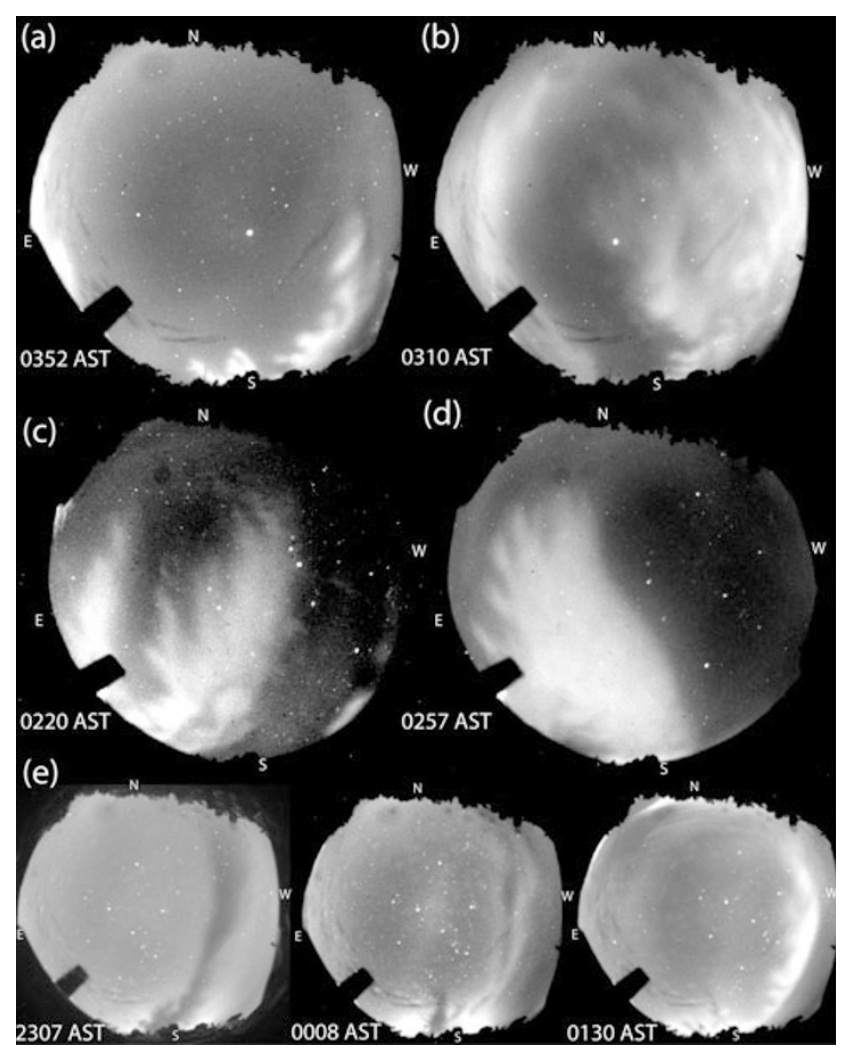

Fig. 14. Propagating (cloud-like) enhancements (a) from 26 to 27 January 2004, (b) from 21 to 22 January 2004, (c) from 16 to 17 January 2005, and (d) from 17 to 18 December 2004. Inversion flux tube from 25 to 26 December 2003 shown in (e).

south emigrams; due to its intensity, the event can also be seen in the 557.7-nm images. In the literature, the brightness waves are related to a lowering of the F-region due to reversal of the meridional winds from equatorward to poleward that results from the MTM pressure bulge (which is thought to be formed by a nonlinear interaction between the higher tidal modes of the thermospheric winds and the diurnal cycle of F-region ionization) (Herrero and Meriwether, 1980; Colerico et al., 1996). The bright vertical lines in emigrams at around 9:00 p.m. 1:00 a.m. and 4:00 a.m. are due to clouds passing suddenly through the image.

Figure 14 shows a second class of enhancement events, with Fig. 14(a)-(d) showing various growing and propagating finger-like enhancement structures and Fig. 14(e) showing a different phenomenon that is a typical inversion event. The equatorial plume-like depletion structure slowly turns into an enhancement tube starting from the edges, as can be seen in the second image. These have recently been called inversion flux tubes by C. Martinis, indicating the rapid descent of the local F-layer filling the depleted tubes (Makela, 2004b).

\section{Current and Future Work}

Other than the image processing techniques, the current research is mainly focused on the analysis of the important Allsky imager results with the collaboration of other instruments. Particular emphasis is given to lidar and radar. Lidar is used along with the wave activity seen in $557.7 \mathrm{~nm}$ to gain a better understanding of the wave parameters, seed- ing mechanisms, and wave motion. Also, as can be seen in the significant Results section, radar is most useful in tracking the vertical structure and motion of the F-region plasma depletion or enhancement events seen in the 630-nm filter.

Another current project aims to better categorize the events in each filter in terms of the relevant science (such as plasma bubbles, plumes, equatorial spread-F (ESF), gravity waves, ducted waves). The online logbook along with the other instruments (lidar, radar, FPI, etc.) will be very useful in this type of effort. Numerical modeling of the structures seen in the images is another issue that is essential to this type of research and which is also a part of ongoing research.

\section{Conclusions}

In this paper, we introduce the Penn State Allsky imager (PSASI) to the scientific community as a useful tool in ionospheric research. In the first part, we introduce airglow science and Allsky imaging briefly for those readers who are new to this specific area. We then provide detailed information on PSASI, including the specifications, the hardware (optical and support), and software system. The PSASI website, which is publicly accessible, is introduced to the community. Brief information on basic data processing techniques commonly used in the Allsky imaging area are listed. In order to ease the access to important data, some very useful statistics, such as quantitative and qualitative information on the data collected, are provided in the figures and tables. In addition, a calendar that shows the most spectacular events along with the filter used is supplied for the benefit of interested users in the community. Finally, we present several of those spectacular events from different filters along with brief comments to demonstrate the usefulness of Allsky imaging with PSASI in ionospheric research. The paper concludes by explaining on-going research (which involves a paper on how to automatically track the swinging radar beam's location in the Allsky images) and future work to be done (e.g. modeling, mesospheric waves and categorization).

Acknowledgments. This effort was supported under NSF Grant ATM 04-13009 to Pennsylvania State University. The Arecibo Observatory is part of the National Astronomy and Ionosphere Center which is operated by Cornell University under cooperative agreement with the National Science Foundation. In particular, we also thank to the Arecibo staff, especially Raul Garcia; and Jonathan Makela from University of Illionis for their helpful efforts.

\section{References}

Behnke, R. A., Vector measurements of the ion transport velocity with applications to the $\mathrm{F}$ region dynamics, Ph.D thesis, Rice University, Houston, Texas, 1970.

Behnke, R. A. and R. M. Harper, Vector measurement of $F$ region ion transport at Arecibo, J. Geophys. Res., 78, 8222-8234, 1973.

Chung, J.-K., Y. H. Kim, and Y.-I. Won, Observation of mesospheric waves with an all-sky camera in Korean Peninsula, Adv. Space Res., 32, 825830, 2003.

Colerico, M. J., M. Mendillo, D. Nottingham, J. Baumgardner, J. Meriwether, J. Mirick, B. W. Reinisch, J. L. Scali, C. G. Fesen, and M. A. Biondi, Coordinated measurements of $\mathrm{F}$ region dynamic related to the thermospheric midnight temperature maximum, J. Geophys. Res., 101, 26783-26793, 1996.

Colerico, M. J. and M. Mendillo, The current state of investigations re- 
garding the thermospheric midnight temperature maximum (MTM), $J$. Atmos. Solar-Terr. Phys., 64, 1361-1369, 2002.

Herrero, F. A. and J. W. Meriwether, 6300-Å airglow meridional intensity gradients, J. Geophys. Res., 85, 4191-4204, 1980.

Kelley, M. C., J. J. Makela, W. E. Swartz, S. C. Collins, S. Thonnard, N. Aponte, and C. A. Tepley, Caribbean ionosphere campaign, year one: Airglow and plasma observations during two intense mid-latitude spread-F events, Geophys. Res. Lett., 27, 2825-2828, 2000a.

Kelley, M. C. and J. J. Makela, A. Saito, On the electrical structure of airglow depletion/height layer bands over Arecibo, Geophys. Res. Lett., 27, 2837-2840, 2000b.

Kelley, M. C., J. J. Makela, and A. Saito, The mid-latitude F region at the mesoscale: some progress at last, J. Atmos. Solar-Terr. Phys., 64, 15251529, 2002.

Kelley, M. C., C. Haldoupis, M. J. Nicolls, J. J. Makela, A. Belehaki, S. Shalimov, and V. K. Wong, Case studies of coupling between the E and $\mathrm{F}$ regions during unstable sporadic-E conditions, J. Geophys. Res., 108(A12), 1447, doi:10.1029/2003JA009955, 2003.

Livneh, D. J., I. Seker, J. D. Mathews, and F. T. Djuth, Continuous quasiperiodic thermospheric waves over Arecibo, J. Geophys. Res., 2007 (submitted).

Makela, J. J., M. C. Kelley, S. A. González, N. Aponte, and R. P. McCoy, Ionospheric topography maps using multiple-wavelength all-sky images, J. Geophys. Res., 106, 29161-29174, 2001.

Makela, J. J., B. M. Ledvina, M. C. Kelley, and P. M. Kintner, Analysis of the seasonal variations of equatorial plasma bubble occurrence observed from Haleakala, Hawaii, Ann. Geophys., 22, 3109-3121, 2004a.

Makela, J. J., A review of imaging low-latitude ionospheric irregularity processes, Review for CEDAR, 2004b.

Makela, J. J., Image processing techniques for Allsky imaging, via personal contact, $2004 \mathrm{c}$.

Makela, J. J., Geomagnetic model field line figures, via personal contact, 2006.

Mathews, J. D., D. W. Machuga, and Q. Zhou, Evidence for electrodynamic linkages between spread-F, ion rain, the intermediate layer, and sporadic E: results from observations and simulations, J. Atmos. Solar-
Terr. Phys., 63, 1529-1543, 2001a.

Mathews, J. D., S. Gonzales, M. P. Sulzer, Q.-H. Zhou, J. Urbina, E. Kudeki, and S. Franke, Kilometer-scale layered structures inside spreadF, Geophys. Res. Lett., 28, 4167-4170, 2001 b.

Mendillo, M., J. Baumgardner, D. Nottingham, J. Aarons, B. Reinisch, J. Scali, and M. C. Kelley, Investigations of thermospheric-ionospheric dynamics with 6300-^̊ images from the Arecibo Observatory, J. Geophys. Res., 102, 7331-7343, 1997.

Rest, A., L. Mündermann, R. Widenhorn, E. Bodegom, and T. C. McGlinn, Residual images in charged-coupled device detectors, Rev. Sci. Instruments, 73, 2028-2032, 2002.

Sahai, Y., P. R. Fagundes, and J. A. Bittencourt, Transequatorial F-region ionospheric plasma bubbles, J. Atmos. Solar-Terr. Phys., 62, 1377-1383, 2000.

Seker, I. and J. D. Mathews, Night-time airglow science and all-sky imaging by the Penn State all-sky imager at Arecibo, Student poster for the CEDAR workshop at Santa Fe, New Mexico, USA, 2004.

Smith, S. M., M. J. Taylor, G. R. Swenson, C. Y. She, W. Hocking, J. Baumgardner, and M. Mendillo, A multidiagnostic investigation of the mesospheric bore phenomenon, J. Geophys. Res., 108(A2), 1083, doi:10.1029/2002JA009500, 2003.

Smith, S. M., J. Friedman, S. Raizada, C. Tepley, J. Baumgardner, and M. Mendillo, Evidence of mesospheric bore formation from a breaking gravity wave event: simultaneous imaging and lidar measurements, $J$. Atmos. Solar-Terr. Phys., 67, 345-356, 2005.

Taylor, M. J., A review of advances in imaging techniques for measuring short period gravity waves in the mesosphere and lower thermosphere, Adv. Space Res., 19, 667-676, 1997.

Wiig, J., The Communications and Space Sciences Laboratory All-Sky Imaging System at Arecibo Observatory-Installation, data acquisition and web publishing, Master's Thesis, The Department of Space Physics at Umeå University, Kiruna, Sweden, 2004.

I. Seker (e-mail: ius102@psu.edu), J. D. Mathews, J. Wiig, P. F. Gutierrez, J. Friedman, and C. Tepley 